\title{
Early clinical pathologists 5: The man behind Hassall's corpuscles
}

\author{
C Ortiz-Hidalgo
}

Department of

Histopathology, University College Hospital and Middlesex School of Medicine, University WC1E 6JJ

C Ortiz-Hidalgo

Correspondence to: Dr Carlos Ortiz-Hidalgo, Faculty of Medicine, National Autonomous University of México Ciudad, Universitaria Coyoacáh 04510, México DF, Mexico

Accepted for publication 7 February 1991 Street, London Department of Histology,

The characteristic small corpuscular bodies composed of concentric, squamous-looking epithelial cells, found in the medulla of the thymus, were described by Hassall in $1849 .{ }^{1} \mathrm{He}$ was, however, a prolific researcher, and among other things, he also described the hyaline deposits observed on the posterior surface of Descement's membrane at the corneal margins associated with senescence. These structures are known as guttate ophttalmicae or HassallHenle's warts. ${ }^{2}$

Arthur Hill Hassall (fig 1) was born in Teddington, Middlesex, England on 13 December 1817. He was the youngest of five children of Thomas and Ann Hassall. ${ }^{3}$ Influenced perhaps by his grandfather, father, and elder brother, who all were doctors, Hassall studied medicine in Ireland. He received his first diploma (in midwifery) in 1837 from the Dublin School of Medicine, where he was taught by many prominent physicians and surgeons of the time like Harrison, Apjohn, Colles, Stroke, Graves and Corrigan. In 1839

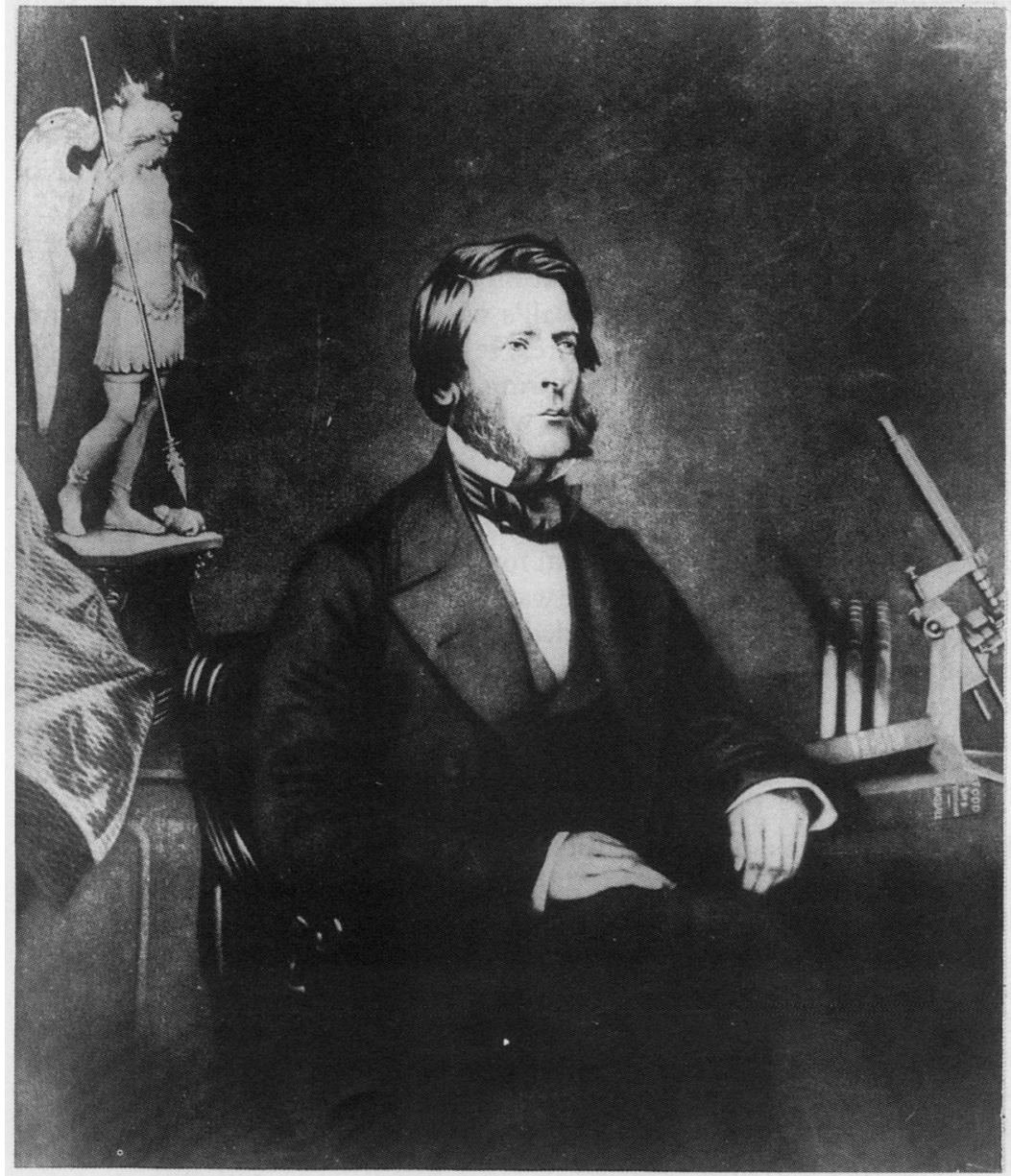

Figure 1 Arthur Hill Hassall MRCS, LSA, MB, MD (1817-94). Courtesy of the Wellcome Institute. he qualified as MRCS, LSA in 1841, MRCP in 1851 , and obtained the $M B$ and $M D$ degrees of London University in 1848 and 1851, respectively. ${ }^{34}$

Back in London, Hassall practised with his father as a physician. His first marriage was on the 26 May 1894 to Fanny du Corron ${ }^{3}$ and they lived in 32 Addison Road, Notting Hill, now 37 Addison Avenue. ${ }^{34}$

Since his student days, Hassall had been very interested in the use of the microscope. Once married and settled in his new home, Hassall wrote: "I determined to apply the microscope to some subject of more professional interest and wider and more general importance. I therefore commenced the examination of some of the tissues of the human body and being charmed and fascinated by what I saw, resolved to microscopically examine systematically all the fluids, tissues and organs of the body . .."5

Hassall made numerous visits to the post mortem room of St George's Hospital to obtain tissue for his observations. ${ }^{3}$ The result of this work culminated in the publication of several papers in the Lancet in 1848 and 1849 and then a two volume book The Microscopic Anatomy of the Human Body in Health and Disease which was published by Samuel Highly in 1849 (fig 2). ${ }^{1}$ One volume consists of text and the other of beautiful colour plates drawn by his collaborator, Mr Harry Miller, from Hassall's own histological preparations. Hassall's microscopic anatomy of the human body was one of the pioneer text books devoted to histology.

It is in the section on the thymus in which he described the distinctive structures, today known as "Hassall's corpuscles". Using his own words, "... The thymus, although usually spoken of and described as a single organ, is in reality double, and consists of two distinct glands united to each other in the middle line by cellular tissue only ... is constituted of numerous, probably some hundred follicles . . . the "milky fluid" contained in the follicles and reservoir is made up, to a great extent, of an immense number of granular nuclei, as well as numerous cells of large size, which do not appear hitherto to have been either described or figured in satisfactory manner... many of these cells contain several granular nuclei, each of which is surrounded by one or more concentric lamellae ..." Hassall shows a drawing of these structures on plate LXI, figure 10 in the second volume of his book (fig 3). ${ }^{1}$

These characteristic structures, found in the medulla of the thymus, were named as "the concentric corpuscles of Hassall" by Friedrich 


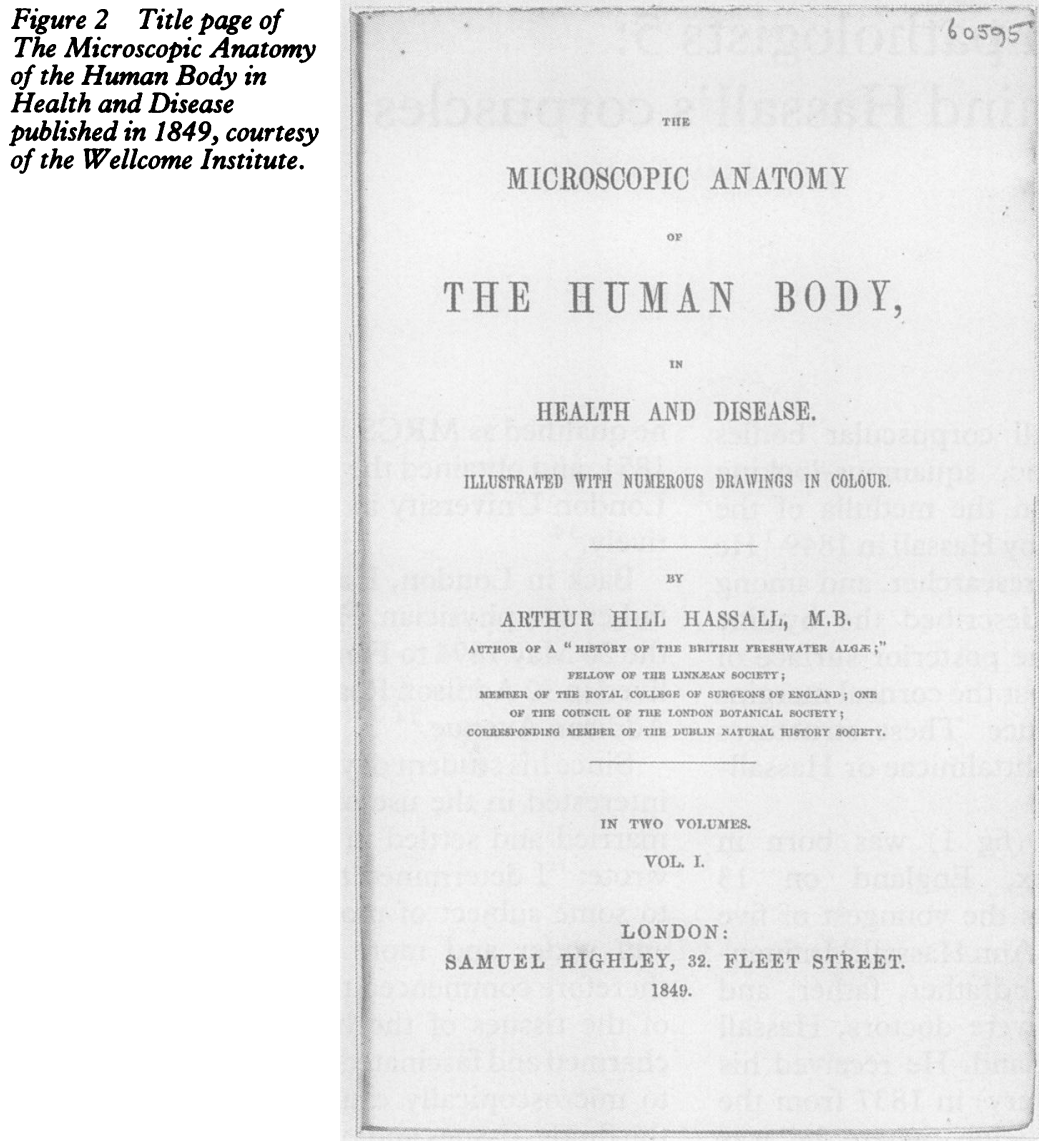

Figure 2 Title page of of the Human Body in Health and Disease published in 1849, courtesy of the Wellcome Institute.

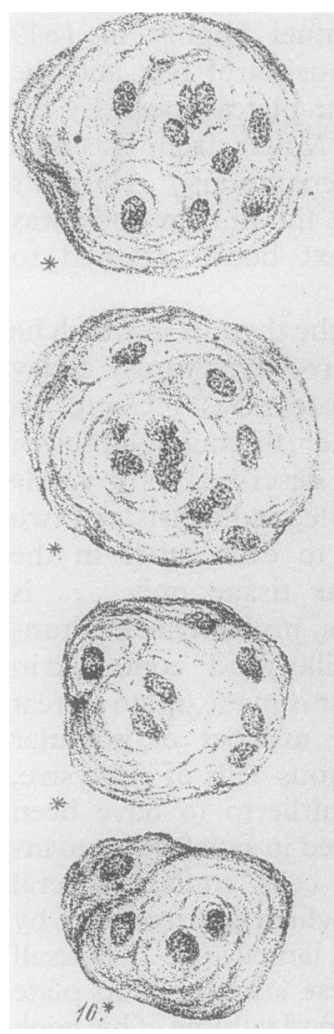

Figure 3 Original drawing of the concentric corpuscles of the thymus. Courtesy of the Wellcome Institute.
Henle. It has been said that these characteristic structures had also been described by Virchow, and are sometimes referred to as HassallVirchow corpuscles. ${ }^{2}$

Although immortalised by the description of the thymic corpuscles, Hassall made many other significant contributions to medicine. Lung disease was one of his many interests. He was the author of one of the few works in the English language devoted to the subject of inhalation as practised in cases of lung and throat diseases. ${ }^{6}$

Perhaps much of his interest in lung disease might have arisen because he suffered from pleurisy (in his own words, "fibroid phthisis of the right lung") from tuberculosis caught while he was a medical student. ${ }^{37}$ After a severe episode of haemoptysis, he spent some time in Ventnor, Isle of Wight, to convalesce. He noted with surprise that there was no institution for the treatment of respiratory diseases in the locality and thus decided to establish a hospital for respiratory diseases, advocating the open air treatment that was so much in vogue at the time. $^{6}$

The Royal National Hospital for Consumption and Disease of the Chest in Ventnor was opened to patients in 1868 and turned out to be a brilliant success. ${ }^{3}$ A marble tablet in the entrance to the lodge recorded the foundation of the hospital by Hassall. In 1964 the patients were moved to the "Hassall ward" in St Mary's Hospital in Newport, Isle of Wight, which had been built to replace the original hospital. ${ }^{3}$

Pathology was another area of medicine in which Hassall was successful. He was the first to observe and explain the frequent presence of urinary sediments, like calcium phosphate and the blue pigment indigo in some pathological conditions. ${ }^{8-10}$ In 1859 he published The Urine in Health and Disease, a second edition of which appeared in 1863." ${ }^{11}$ This dealt mainly with the chemistry of urine, with hundreds of colour plates drawn by himself and by Miller. In urinary pathology the eponymous term, "Hassall's corpuscles," was once used to describe the distinctive deposits seen in the urinary bladder of patients with cystitis, first described by Hassall in $1853 .^{7}$

In 1850 Hassall used the microscope to examine the question of food adulteration. Thomas Wackley, surgeon to the Royal Free Hospital and the Lancet's first editor, conceived a commission to investigate, by analytic techniques, the adulteration of food and drink in London. ${ }^{12}$

Back in the 1820s it was suspected that much food and drink (milk and water) had been adulterated. The problem was how to prove it. Hassall, commissioned by Wackley, employed his Ross microscope to examine a wide variety of food, drink, and drugs. He found that coffee was often mixed with chicory, roasted potato, corn or beans; tea with sloe leaves coloured with iron salts; and bread often contained alum. ${ }^{12} \mathrm{He}$ found a large amount of debris and living organisms in water. ${ }^{13}$

These findings were published in the Lancet, and afterwards he wrote a book dealing with the microscopic examination of the water. ${ }^{14}$ These reports astonished public opinion. It was once written: "we do not doubt or deny the good services which Dr Hassall has rendered to the public; but we tremble either to eat or drink after his book has come to our hands!"4 Hassall's reports were the basis of the reconstruction of London's water supply, the adoption of the Food and Drug Adulteration Act of 1875, ${ }^{7}$ and the effective measures taken to prevent adulteration by parliament. ${ }^{12}$

Hassall's work with the microscope did not stop here. He conducted a number of investigations during the cholera epidemic of 1853-54 during which he observed the "comma shaped" bacillus, characteristically seen in this disease. $^{3}$ To this end he worked with his microscope in a ward of St Bartholomew's Hospital for cholera patients, and obtained the "rice water discharge" and immediately examined it. $^{7}$

His first laboratory for clinical analysis seems to have been established in 1854 at 66 Park Street, Grosvenor Square, London. ${ }^{3} \mathrm{He}$ taught many young English chemists and physicians who held him in high esteem. Some of the doctors that trained with him included: $\mathbf{M r}$ Alfred H Allen, Mr Otto Hehner, Dr John Muter, Dr A Angell, Mr WD Borland, and Mr RJ Friswell. ${ }^{34}$

In the 1850s Hassall wrote a very fine work on organic chemistry entitled Human Crystallography. This book contained descriptions and no less than 300 colour illustrations (drawn by himself with a camara lucida) of all the crystalline compounds within the fluids of the human body-namely, blood, bile, semen, milk, urine, pus, etc. ${ }^{15}$ 
Among the appointments he held were those of senior physician to the Royal Free Hospital (where a ward has been named after him), and medical referee to the United Kingdom Life Assurance Company. Moreover, he was a public analyst to the Isle of Wight and vice president of the Society of Public Analysts in 1875. He was also consulting physician to the Royal National Hospital for Consumption Disease of the Chest, in Ventnor, Isle of Wight, until his death. When he left the Isle of Wight to move to the Italian Riviera in 1877, he was presented with a service of silver and a purse of 300 guineas in recognition of his invaluable work to the hospital. ${ }^{7}$

Apart from his contributions to medicine, Hassall made an impact in the world of zoology, meteorology, and botany. ${ }^{3}$ As a medical student he collected a number of zoophytes and corallines from Dublin Bay. He discovered many new species of algae and zoophytes, and published the well known classical book entitled $A$ History of British Fresh-water Algae. ${ }^{16}$ This book contained a complete account of the modes of reproduction, growth, vitality, distribution, uses, species and classification for this most distinctive class of plants. In fact, the generic term Hassallia is given to various forms of algae like Hassallia ocellata, Hassallia compacta, and Hassallia turfosa, to name but a few.

It was because of bad health that he was forced to leave England and he settled, with his second wife, Alice Margaret, at San Remo, Italy, in $1877 .^{3}$ There, Hassall enjoyed the highest reputation as a skilful doctor. He was in active practice until a few weeks before his death. Hassall died almost in poverty in San Remo on 9 April 1894 at the age of $77 .^{3}$

Arthur Hill Hassall was a true gentleman. He was an honest and highly cultured man, with an unfailingly polite manner, a benevolent smile, and an easy going disposition. Work was his pleasure and recreation." "Success in my profession", "was my chief aim and desire ...", and he certainly accomplished it. He left behind an enormous body of work as is shown by the huge literary output of over 200 papers and books covering a wide range of medical and scientific subjects, showing only his strenuous and dedicated professional life.

His scientific achievements have marked Hassall as one of the most outstanding physicians of his time. This remarkable man's career will long be remembered by all members of the medical profession.

I thank Dr Martin Young for a critical reading of the manuscript. Thanks are also extended to the Wellcome Institute for the History of Medicine for providing the information that made this paper possible.

1 Hassall AH. The microscopic anatomy of the human body in health and disease. London: Samuel Highly, 1849.

2 Various. International dictionary of medicine and biology. New York: Willey Medical Publications, 1986.

3 Gray E. By candlelight. The life of Dr Arthur Hill Hassall. London: Robert Hale, 1983.

4 Clayton EG. Arthur Hill Hassall. Physician and sanitary reformer. London: Baillière Tindall and Cox, 1908.

5 Hassall AH. The narrative of a busy life. London: Longmans and Co, 1893.

6 Hassall AH. The inhalation treatment of disease of the organs of respiration. London: Longmans and $\mathrm{Co}, 1885$.

7 Obituary. Arthur Hill Hassall, MD. Lancet 1894;977-8: 3671-96.

8 Hassall AH. On the frequent occurrence of phosphate of lime, in the crystalline form, in human urine and on its pathological importance. Proc Roy Soc 1859-60;10:281-8.

9 Hassall $\mathrm{AH}$. On the frequent occurrence of indigo in human urine, and on its chemical and physiological relations. Proc Roy Soc 1853;6:327-31.

10 Hassall AH. On the frequent occurrence of indigo in human urine, and on its chemical, physiological and pathological relations. Phil Trans 1854;144:294-310.

11 Hassall AH. The urine in health and disease. London: 1859.

12 Forrester J. The Lancet's analytical sanitary commission. Lancet 1978;ii: $1360-2$.

13 Hassall AH. Memoir on the organic analysis or microscopic examination of water. Lancet $1850 ; \mathrm{i}: 230-5$.

14 Hassall AH. An examination of water supplied to the inhabitants of London and the surburban districts. London: Samuel Highly, 1850 .

15 Hassall AH. Human crystallography. London: Samuel Highly, 1850.

16 Hassall AH. A history of British fresh-water algae. London: Samuel Highly, 1849. 